\title{
SOME IMPORTANT ECOLOGICAL ASPECTS OF THE DIRECTIVE 2000/60
}

\author{
K. HADJIBIROS*
}

Received: 20/09/04

Accepted: 30/11/04

\author{
National Technical University of Athens \\ Hydraulic and Maritime Engineering, School of Civil Engineering \\ Iroon Polytechniou 5, 15780 Athens, Greece
}

\begin{abstract}
The Water Framework Directive 2000/60 is a characteristic example of modern European environmental policy, based upon advanced environmental principles. Is reflects a gradual convergence between actual European political consensus on environmental matters and positions of the green movements. Most important ecological dimensions of the WFD 2000/60 are: the consideration of water as a social and ecological good; the target of upgrading ecological quality of all water bodies; the recovery of water cost as a regulating instrument for rational management; the development of protection and suitable organization of the water uses, as well as of a collective responsibility for management in the level of water basin; the investigation of biological together with geomorphologic and physicochemical parameters in the framework of a reliable monitoring system.
\end{abstract}

KEYWORDS: rational management, ecological quality, water basin, green positions, social good, cost recovery

\section{INTRODUCTION}

The modern environmental policy, which has been brought forward by most of the developed countries and especially by the European Union, is evolving during last years in a way that leads to gradual convergence with green positions. Having sustainability as the main target, modern environmental policy is based on the principles of high environmental quality, of prevention or of precaution, as well as of the polluter's responsibility. The European Directive $2000 / 60$ is an important statute that reflects, with the clearer way till today, the above mentioned principles. It represents a typical example of an institutional action, which promotes a more qualitative and expensive economic development and implies a set of significant administrative, scientific/technological and economic changes.

It is remarkable that the statements of the Directive are significantly advanced in the matters of water resources conservation, so that they come very close to the corresponding positions of green movement. However, these statements have won the accession of the complicated decision-making mechanisms of the European Union that generally promote compromises between opposite trends. The critic, which says that the Directive has been composed by the greens and therefore it has excessive ecological demands, overlooks the actual european political reality and it just tries to feed an unproductive confrontation between the supporters of development and those of environment. Although this opposition is always present, it can balance every moment in a suitable compromise. The fact that the Directive was voted by the responsible bodies, European Council and Parliament, shows the current level of consensus, that is to say that big steps have been made towards the political objective of a better environmental quality. Europe is presented henceforth mature for a more rational management of its water resources. Indeed, it might be that the implementation of certain provisions of the Directive encounters tougher difficulties and it delays in some member states. Moreover it 
might be necessary the time schedule to be prolonged. However, these should be considered as additional compromises between the opposite tendencies. In any case, the Directive is based on the requirements of a big part of the common european opinion for a high level protection of the environment. Most advanced statements in such issues meet a powerful social support, mainly in countries such as Denmark, Finland, Germany, Netherlands and Sweden.

\section{THE WATER AS A SOCIAL AND ECOLOGICAL GOOD}

The Directive is not based on a biocentric philosophy, although it has a clearly friendly to the environment tendency. At first, it aims to serve human needs, which, however, have to be considered in an integrated framework. Fundamental idea of the Directive is that the water does not constitute "a commercial product like any other", but that it also has an ecological and a social dimension. It is assumed to be a heritage that the users owe to protect, to defend and to handle with the suitable way. To accept the water as an ecological good is opposed to an argument widely spread in techno-economic circles, which believe that the water is lost if it is not used for a productive purpose. According to the spirit of the Directive, the water is an element of a wider system, it always goes somewhere and does something where it goes. So any exploitation of it involves some environmental cost.

Better understanding of the integrated approach necessitates a useful distinction between three different phenomena that are related to lack of water in general. The rainlessness is a climatic phenomenon, where the rainfall is less than expected. The drought is an ecological phenomenon, where the presence of water is inferior to the needs of ecosystems. The water shortage is a social phenomenon, where the people's water needs are higher than the available water resources. The water's rational management is proposed as an appropriate method to resolve the social problem of the water shortage.

\section{THE RECOVERY OF THE WATER COST}

An important tool for the rational management is the water pricing, which can contribute considerably in the responsible and not wasteful use, as it suits in a social good. According to the Directive, the use of the water should include the recovery of its cost. It is noticed that the approach followed by the Directive corresponds in the classic reformistic european ideology, combining elements of a liberal approach with socialistic elements. Therefore, any waste of water, even provoked by the poor consumer, should be discouraged with the corresponding payment, because the whole society is burdened by any lack of water saving and, especially, financially weak people are more vulnerable to its effects. In the case e.g. of the water for rural use, identification of excessive discounts in water price is needed. Moreover, the restriction of free irrigation water will encourage the necessary saving.

This approach is environmentally sound for two reasons: firstly because it rationalizes the use of the resource, making the inefficient use less interesting and contributing consequently in water saving. Secondly, because it justifies the inclusion of exterior components in water cost and it creates, consequently, possibilities of financing measures for the conservation and the rehabilitation of the resource under exploitation.

The recuperation of water cost is not allowed to have a clearly commercial character, because the Directive denies that the water is simply a commercial product. The water pricing basically plays a regulating role, which constitutes the necessary condition for the rational management.

\section{MAINTENANCE AND UPGRADE OF ECOLOGICAL QUALITY}

The Directive is based on the scientific ascertainment that water constitutes a part of ecosystems and after its use from humans, it returns to ecosystems. By this way, the Directive promotes the cultural step of transition from the exploitation to the management of water resources. Central element of this change is the nomination of ecological quality in fundamental purpose. The maintenance of a high level water quality is necessarily 
related to water quantity, therefore it presupposes a satisfactory hydrologic status of the water bodies.

The ecological quality should generally be improved or, if it is good enough, it should be maintained in the same level, but it is not allowed to degrade. In this point, a matter of comparison emerges. A reference condition can be determined either in a maximalistic way as a pristine situation, e.g. before any human intervention or in a minimalistic way, as an environmental state not significantly degraded, e.g. a pre-industrial not polluted situation or a situation at the beginning of the 20th century.

The examination of quality concerns all kinds of water bodies except open sea, namely the coastal, lotic, lentic, wetland or underground water. It still concerns all the modified or artificial water bodies, as the reservoirs or the irrigatory channels, that are considered thus in a single ecological regard. The general application of rules of management in all water bodies is an important integrated approach. The adjustment of the artificial with the non artificial water bodies, aiming at a maximum ecological quality, is a radical step towards an overpassing of the traditional division between natural and cultural objects. Moreover the Directive contains an additional innovation, the long-term objective of zero pollution in the marine environment. This concerns all the anthropogenic pollutants, while the concentrations of natural substances should be maintained within their natural limits.

\section{A PROGRAM OF MONITORING}

The ecological quality is not just a desirable situation, but it should be controlled by reliable monitoring systems, operating at a constant frequency of measurements. The estimation of quality is done with suitable examination of geomorphologic, physicochemical and biological parameters. The use of biological methods of estimation is an important innovation that offers a more systemic and completed picture of quality. However, the biological assessment of water bodies should not get some privileged place compared to the other approaches.

\section{THE ORGANISATION IN THE LEVEL OF WATER BASIN}

The Directive requires decentralised management, with scientific criteria. The protection and the organisation of the water use should be realised in the level of the catchment area. This makes possible a more completed control of pollution sources, while a suitable care for the conservation of all environmental elements can be organised. In this geographic frame, the planning is realised, the economic and environmental components are examined, the costs and the impacts are evaluated and the measures that concern surface and underground water of the same ecological, hydrologic and hydrogeologic system are coordinated. Thus a collective responsibility for the environmental matters of the basin is established, where the delimitation of problems is based on objective natural data. The supply of sufficient information for the plans and the management practices is imposed, so that the concerned citizens can be involved in the procedures, before final decisions in the level of water basin are taken.

\section{ACKNOWLEDGEMENTS}

The author would like to thank Ms Christina Giannakidou and Efi Hamakioti for their valuable suggestions and help in preparing this text.

\section{REFERENCES}

1. Andreadakis, A. (2002). The importance of a coordinated action for the implementation of the Water Framework Directive 2000/60. Proc. Conf. Water Framework Directive, NTUA, Athens, pp.19-32.

2. Assimacopoulos, D. (2002). The recovery of water cost in Directive 2000/60. Proc. Conf. Water Framework Directive, NTUA, Athens, pp.33-41.

3. Getimis, P. and D. Zikos (2002). Participation of new actors in the water resource management and the role of EYDAP. Proc. $3^{\text {rd }}$ Int. Forum Hydrorama 2002, Athens, p. 382389. 
4. Hadjibiros, K. (2002). The difficulties of changes required by the Directive 2000/60. Proc. Conf. Water Framework Directive, NTUA, Athens, pp.93-97.

5. Hadjibiros, K., P.S. Economidis and Th. Koussouris (1997). Let the fish speak: The ecological condition of major Greek rivers and lakes in relation to environmental pressures, $4^{\text {th }}$ EURAQUA Technical Review, Koblenz, p. 103-123.

6. Tsouni, A., N. Zervos, K. Hadjibiros and A. Andreadakis (2002). An environmental database for the status of freshwater in Greece, Global Nest: the Int. J. 4(1), 1-14.

7. Work Team (1993). Necessary Actions for the Protection of the Environment in Greece, Technical Chamber of Greece and European Commission, Vol. 1,2, Athens

8. Work Team (1996). Management Plan of Water Resources of Greece. Technical Report, Ministry of Development, National Technical University of Athens, Institute of Geological and Mineral Research and Centre for Planning and Economic Research, Athens. 